\title{
Validation of high-resolution melting analysis as a diagnostic tool for endothelin receptor B mutation in American Paint horses and allele frequency estimation
}

\author{
Peres Ramos Badial ${ }^{\mathrm{a}, \mathrm{b}}$, Raffaella Bertoni Cavalcanti Teixeira ${ }^{\mathrm{c}}$, Diego José Zanzarini Delfiol ${ }^{\mathrm{d}}$, \\ Ligia Souza Lima Silveira da Mota ${ }^{\mathrm{e}}$, Alexandre Secorun Borges ${ }^{\mathrm{a}, *}$ \\ ${ }^{a}$ Department of Veterinary Clinical Science, School of Veterinary Medicine and Animal Science, UNESP - Univ Estadual Paulista, Botucatu, SP, Brazil \\ ${ }^{\mathbf{b}}$ Department of Pathobiology and Population Medicine, College of Veterinary Medicine, Mississippi State University, 240 Wise Center Drive, Mississippi State, MS 39762- \\ 6100, USA \\ ${ }^{\mathrm{c}}$ Veterinary Clinic and Surgery Department (DCCV), UFMG Veterinary College, Universidade Federal de Minas Gerais, UFMG, Belo Horizonte, Minas Gerais, Brazil \\ ${ }^{\mathrm{d}}$ Faculdade de Medicina Veterinária, Universidade Federal de Uberlândia, Campus Umuarama, Uberlândia, Minas Gerais, Brazil \\ e Department of Genetics, Institute of Biosciences, UNESP - Univ Estadual Paulista, Botucatu, SP, Brazil
}

\section{A R T I C L E I N F O}

\section{Keywords:}

Frequency of heterozygotes

Endothelin receptor type B

Genotyping

High resolution melting analysis

Overo lethal white foal syndrome

\begin{abstract}
A B S T R A C T
Overo lethal white foal syndrome (OLWFS) is a genetic disorder caused by a dinucleotide mutation in the endothelin receptor type B (EDNRB) gene leading to the death of affected foals shortly after birth. The use of rapid and reliable genetic testing is imperative for the early diagnosis of the mutation avoiding, therefore, either additional suffering or the production of affected animals. In the present study, we developed and validated a high-resolution melting (HRM) genotyping assay to detect the OLWFS causative mutation, and we also determined the frequency of heterozygotes among American Paint horses in Brazil. The HRM genotyping assay resulted in a high sensitivity, specificity, and positive and negative predictive values. The overall estimated frequency of heterozygotes was $21.6 \%$; however, this frequency increased to $89.5 \%$ when considering only overo horses. The HRM assay optimized here was a reliable and suitable method for the detection of the dinucleotide mutation observed in the EDNRB gene resulting in a fast, accurate, and precise diagnostic tool. The causative gene mutation of OLWFS is present in heterozygosity in the American Paint Horse population in Brazil and is highly frequent among overo horses.
\end{abstract}

Among the many coat color patterns in the American Paint Horse (APH) breed, the overo and tobiano are two generally accepted types of white spotting patterns. Horses with the overo pattern usually exhibit a white-spotting pattern that does not cross the back, with extensive white spots on the head and some dark color on feet and legs, whereas the white-spotting pattern in tobiano horses crosses the back and covers the feet, varying portions of the legs, and a small portion of the head [1]. Mutations associated with white-spotted patterns in horses have been identified in EDNRB, KIT, MITF, PAX3 and TRPM1 genes [2-10]. The frame overo spotting pattern occurs in heterozygous horses due to a missense mutation in the first exon of the endothelin receptor type $B$ $(E D N R B)$ gene $[5-7,11]$. Pleiotropic effects such as a white or nearly complete white coat and ileocolonic aganglionosis have been reported as the result of the homozygous mutation [5-7,12]. The condition known as overo lethal white foal syndrome (OLWFS) is a genetic disorder inherited in an incomplete dominant, homozygous lethal fashion. Affected foals exhibit severe colic episodes due to functional intestinal obstruction shortly after birth and invariably die from condition $[13,14]$. Therefore, the rapid diagnosis is imperative to avoid any additional suffering of the animals. More importantly, foreknowledge of the progenitors' genotypes and mating selection are more rational approaches to prevent the production of affected animals. In any case, genetic testing is a useful and auxiliary tool for the early diagnosis of the disease and guidance in the mating selection.

Previous studies used allele-specific PCR approaches either to determine the causative DNA mutation of OLWFS [5-7,15] or to estimate the frequency of heterozygotes [16,17]. Although genotyping PCRbased methods are simple and reliable [18], the technical challenges to obtain optimal PCR primers may cause low PCR efficiency [19]. Also, the post-PCR handling to resolve the genotypes increases the time to

\footnotetext{
${ }^{*}$ Corresponding author. Department of Veterinary Clinical Science, School of Veterinary Medicine and Animal Science, UNESP - Univ Estadual Paulista, Rubião Júnior District, Botucatu, São Paulo, 18618970, Brazil.

E-mail addresses: prbadial@hotmail.com (P.R. Badial), asborges@fmvz.unesp.br (A.S. Borges).
} 
obtain the result and may provide a source of post-PCR contamination. High resolution melting (HRM) of DNA for genotyping purposes relies on the analysis of the melting temperature to differentiate among genotypes; therefore, a robust and specific PCR technique is critical for the analysis [20]. The HRM analysis also is a closed-tube method, which eliminates processing between amplification and analysis and prevents the risk of cross-contamination [20]. In addition, HRM assay is a simple, rapid, and low-cost analytical technology providing reliable, accurate, and precise genotyping results [20-23].

The objective of the present study was two-fold, first to develop and optimize an HRM genotyping assay to detect the dinucleotide mutation in the $E D N R B$ gene; and, secondly, to determine the frequency of heterozygotes for the causative mutation among American Paint horses in Brazil.

This study was approved by the São Paulo State University Institutional Animal Care and Use Committee (protocol n.30/2010). To estimate the frequency of heterozygotes among APHs in Brazil, the sample size was calculated using an open source software (OpenEpi version 3.03, available in www.OpenEpi.com) considering the Brazilian population size of 17,174 APHs [24], anticipated frequency of heterozygotes of $50 \%$, absolute precision of $10 \%$, 95\% confidence interval, and random sampling. Based on this calculation a minimum of 96 horses was necessary to estimate the frequency of heterozygotes in this population. Blood was collected from 99 horses, and they were classified phenotypically regarding their coat color pattern as previously described [16]. Thirteen extra blood samples that had been collected throughout the years were used as controls (i.e., three samples from affected foals [homozygous dominant], five samples from frame overo horses [obligate heterozygotes], and five samples from solid-colored horses [homozygous recessive]) for the optimization of the real-time PCR and HRM assays. Genomic DNA was isolated using a commercially available kit (Illustra Blood GenomicPrep Mini Spin Kit, GE Healthcare Life Sciences, PA, USA). The relative purity and quality of the isolated DNA were determined by spectrometry (Nanodrop ${ }^{\mathrm{TM}}$, 2000 Spectrophotometer, Thermo Scientific ${ }^{\mathrm{TM}}$, MA, USA). All purified DNA samples were immediately stored at $-80^{\circ} \mathrm{C}$ until processing.

The genotypes of the control samples were confirmed before the optimization of the real-time PCR and HRM assays. Briefly, PCR was performed in duplicate to amplify a 175 base pair (bp) amplicon of the equine $E D N R B$ gene (Gene ID: 100033875) containing the dinucleotide mutation. The PCR reaction contained $10 \mu \mathrm{L}$ of a commercial master mix (GoTaq Green Master Mix, Promega, WI, USA), $0.3 \mu \mathrm{M}$ of each forward (5'-GAACCATCGAGATCAAGGAGAC-3') and reverse (5'-TGCA GCAGAGTCTCCCAGAGC-3') primers [5], $2 \mu \mathrm{L}$ of template DNA, and nuclease-free water (q.s.p $20 \mu \mathrm{L}$ ). The amplification was performed with an initial denaturation step at $95^{\circ} \mathrm{C}$ for $2 \mathrm{~min}$. The samples were then subjected to 35 cycles of the following conditions: $95^{\circ} \mathrm{C}$ for $30 \mathrm{~s}$, annealing at $60^{\circ} \mathrm{C}$ for $30 \mathrm{~s}$, and extension at $72{ }^{\circ} \mathrm{C}$ for $1 \mathrm{~min}$. The final extension was performed at $72{ }^{\circ} \mathrm{C}$ for $7 \mathrm{~min}$. The amplified PCR products were purified and sequenced for genotype confirmation using PCR primers and Sanger sequencing.

Four primer sets were designed (Primer Express ${ }^{\circledR}$ Software 3.0, Applied Biosystems ${ }^{\circ}$, CA, USA) to amplify fragments smaller than 150 bp of the equine EDNRB gene (Gene ID: 100033875) containing the dinucleotide polymorphism (Table 1) [5]. Assay development and optimization were carried out using the control samples and HPLCpurified primers under several concentrations $(0.1 \mu \mathrm{M}-0.5 \mu \mathrm{M})$. The adequate primer set amplified a specific fragment with no primer dimer generation and standard deviation (SD) of the raw $\mathrm{Ct}$ values $\leq 0.25$ in the real-time PCR allowing accurate genotype call by the HRM software. The selected primer set amplified an 86 bp amplicon (Table 1). The DNA concentration of all unknown and control samples was normalized to $20 \mathrm{ng} / \mu \mathrm{L}$. All reactions were carried out in triplicate in a total of $20 \mu \mathrm{L}$ each, containing $0.2 \mu \mathrm{M}$ of each forward and reverse primer, $2 \mu \mathrm{L}$ of template DNA, $10 \mu \mathrm{L}$ of master mix (MeltDoctor ${ }^{\mathrm{TM}} \mathrm{HRM}$ Master Mix, Applied Biosystems , CA, USA) and nuclease-free water q. s.p. In addition, a no template control and at least one control sample of each genotype were included in triplicate on each plate. PCR conditions were: initial denaturation at $95^{\circ} \mathrm{C}$ for $10 \mathrm{~min}$ and 40 cycles at $95^{\circ} \mathrm{C}$ for $15 \mathrm{~s}$ and $60^{\circ} \mathrm{C}$ for $60 \mathrm{~s}$, followed by a high resolution melting curve from $65{ }^{\circ} \mathrm{C}$ to $95^{\circ} \mathrm{C}$ with $0.1^{\circ} \mathrm{C}$ increase at each step. The amplification of specific alleles was confirmed by melting curve analysis.

High resolution melting analysis was performed with an HRM software (HRM Software 2.0.1, Applied Biosystems ${ }^{\circ}$, CA, USA). Active melt region was set between $0 \%$ fluorescence intensity at post-melting region and $100 \%$ fluorescence intensity at the pre-melting region. The pre-melting and post-melting regions were set between $75.25{ }^{\circ} \mathrm{C}$ and $75.75^{\circ} \mathrm{C}$ and $82.0^{\circ} \mathrm{C}$ and $82.5^{\circ} \mathrm{C}$, respectively. The HRM software algorithm used those parameters to place all unknown samples into one of the three possible DNA variants. All samples were also sequenced to confirm the HRM assay results using the conventional PCR protocol described above. Validation of the HRM technique was carried out by analysis of the sensitivity, specificity, repeatability, and reproducibility as previously described [21]. Sensitivity and specificity were calculated by comparing the HRM against sequencing results. Repeatability was analyzed by placing ten replicates of each control genotype within the same run. Reproducibility was analyzed as described for repeatability on five different days.

All primer sets designed for real-time PCR-HRM assay amplified specific fragments with no primer dimer generation and allowed for accurate genotype call in the HRM analysis. Although all primer sets amplified products with $\mathrm{SD}$ of $\mathrm{Ct}$ values $\leq 0.5$, only one of them achieved the cutoff value established.

Validation of the HRM-based genotyping assay and estimation of the frequency of heterozygotes were performed in 97 out of 99 sampled horses. Those two excluded samples, which were obtained from homozygous recessive horses (confirmed by sequencing), were not submitted to HRM analysis because they obtained higher SD values than the minimum established in our laboratory for real-time PCR-HRM assay. Other real-time PCR approaches, such as gene expression assays or probe-based genotyping assays, are usually less restrictive regarding the SD of technical replicates accepting values up to 0.5 or even higher in some cases. This criterion may be more rigorous than usually practiced for HRM-genotyping assays, but it ensures that HRM analysis is always performed in high-quality real-time PCR data.

Despite the good integrity and apparent purity of the excluded samples (data not shown), the real-time PCR assay used in the present study for HRM analysis resulted in an analytical failure rate of $2 \%(2 /$ 99). Previous studies have demonstrated analytical failure rate of the real-time PCR-HRM analysis between $1.6 \%$ and $5.4 \%$ [21,25]. In one of

Table 1

Primer sets designed for the development and optimization of the real-time PCR-HRM assay.

\begin{tabular}{|c|c|c|c|}
\hline Primer set & Forward $\left(5^{\prime}-3^{\prime}\right)$ sequence & Reverse $\left(5^{\prime}-3^{\prime}\right)$ sequence & Product size (bp) \\
\hline $1^{\mathrm{a}}$ & CAGTAGTGTCCTGCCTAGTGTTCGT & CCGCATGCACTTGTTCTTGT & 86 \\
\hline 2 & CAGTAGTGTCCTGCCTAGTGTTCGT & CAGGCTGGCGATCAAGATATTAG & 116 \\
\hline 3 & GAAAGAACCATCGAGATCAAGGA & CCGCATGCACTTGTTCTTGT & 129 \\
\hline 4 & CCCGTGCGAAAGAACCAT & CGTTCCGCATGCACTTGTT & 140 \\
\hline
\end{tabular}

a Selected primer set utilized in the genotyping assay. 
those studies [21], the analytical failure rate was attributed to inaccurate pipette handling and the correct genotype call was achieved after performing a second HRM analysis. Also, unspecific products, salt concentration, and carryover inhibiting substances may result in inaccurate amplification and aberrant melting curve behavior [26,27]. Although the analytical failure rate described in those studies was attributed to the HRM assay and in this study to the real-time PCR assay due to the more restrictive SD criterion established, we decided to use a similar approach to address possible reasons for the estimated analytical failure rate. We first repeated the real-time PCR-HRM assay a second time in all DNA samples. Genotype calls matched those detected in the first assay; but, we were still not able to reduce SD of raw $\mathrm{Ct}$ values in those three problematic samples. Then, we re-isolated DNA from those three samples and repeated the real-time PCR-HRM assay to address this issue even further, but the results were similar as before. Although it was not possible to determine the exact reason for the SD issue in all trials, it is unlikely that inaccurate pipetting or inhibiting substance may be the culprits for it because all samples were similarly handled and no reduction of the analytical failure rate was observed after performing a second real-time PCR or a new DNA isolation protocol.

HRM allowed the correct identification of all control genotypes, which clustered together in the expected melting temperatures and curve shape profiles (Fig. 1). This result indicates that the HRM assay optimized here is a reliable and suitable method for the detection of the dinucleotide mutation observed in the EDNRB gene. Repeatability and reproducibility analysis of the assay indicated high intra- and interprecision, respectively. High precision of HRM assays was previously attributed to the use of the same reagents, DNA dilution, and normalization setting between runs, which supports the value of HRM-based genotyping assays in the diagnostic routine [21]. The genotypes of the majority of the unknown samples (99\% [96/97]) were correctly identified by the assay indicating high accuracy. Comparing to sequencing results, which was the gold standard method to determine genotypes, the HRM assay resulted in high sensitivity (100\% [19/19]) and specificity $(98.72 \%[77 / 78])$. The HRM assay also resulted in high positive (95\% [19/20]) and negative (100\% [77/77]) predictive values. Previous genotyping [21-23] and mutation scanning studies [23,27,28] have demonstrated high sensitivity, specificity, and positive and negative predictive values of the HRM assay. Similarly to a previous study reporting false positive rates between $1.4 \%$ and $3.4 \%$ of the HRM approach [28], one homozygous recessive horse $(1.28 \%$ [1/78]) was considered homozygous dominant in the present study. This false positive sample was sequenced at least three times for genotype confirmation.

Although the optimized HRM assay was considered highly precise

A

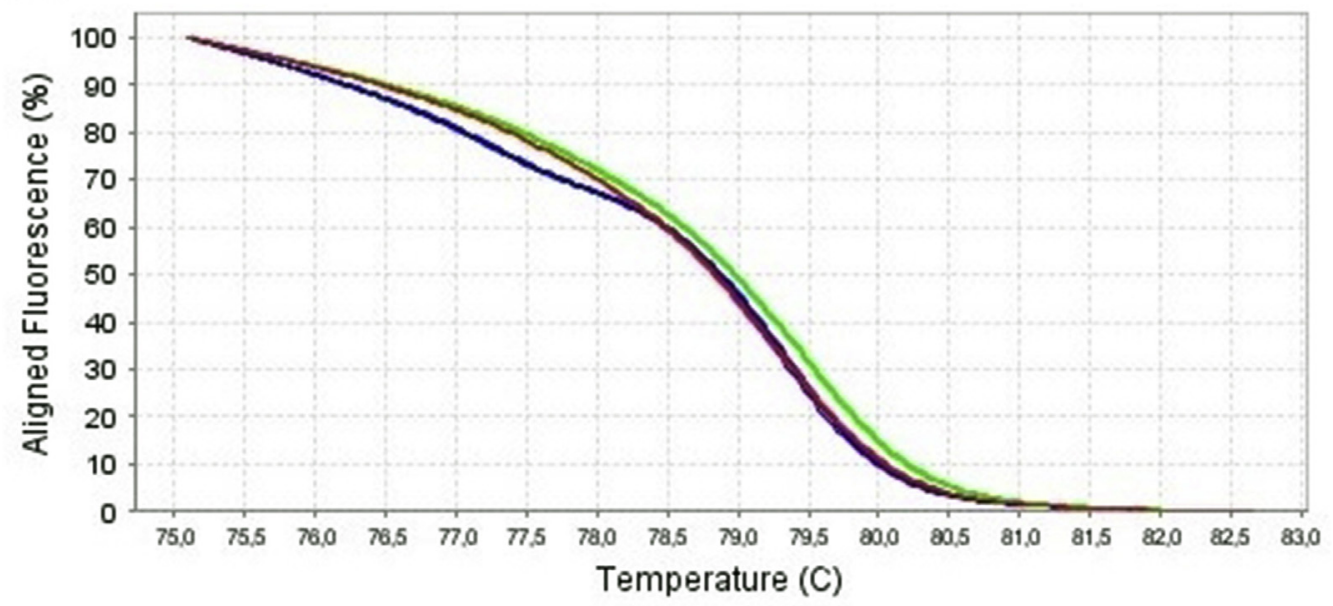

B

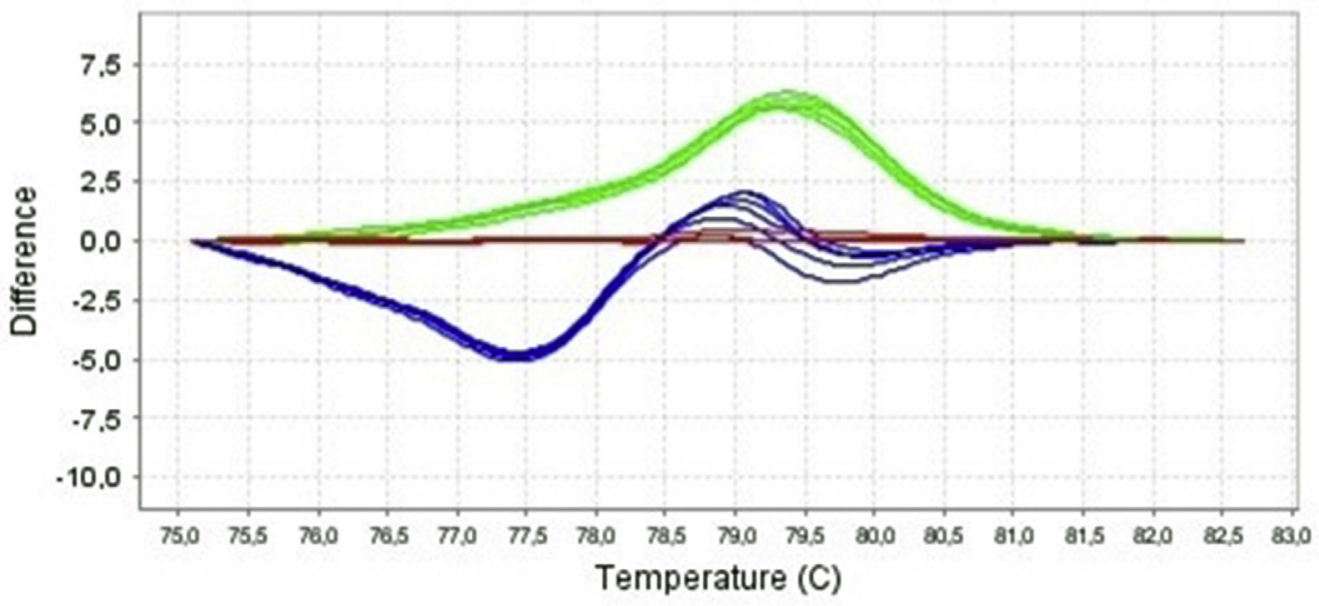

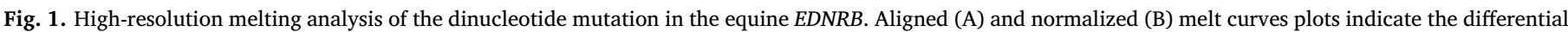

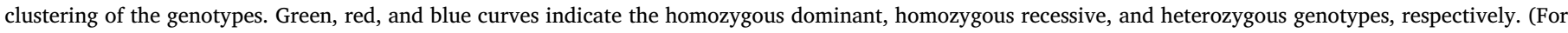
interpretation of the references to color in this figure legend, the reader is referred to the Web version of this article.) 
Table 2

Distribution of the EDNRB mutation among adult Paint Horses according to gender and coat color pattern.

\begin{tabular}{lcll}
\hline & Horses (n) & Homozygous recessive (n) & Heterozygous (n) \\
\hline Gender (n = 97) & & & \\
Female & 83 & 67 & 16 \\
Male & 14 & 11 & 3 \\
Coat color pattern $(\mathrm{n}=97)$ & & \\
Overo & 19 & 3 & 17 \\
Bald-faced overo & 1 & 1 & 0 \\
Calico overo & 6 & 1 & 5 \\
Frame blend overo & 1 & 0 & 1 \\
Frame overo & 7 & 0 & 7 \\
Sabino overo & 3 & 0 & 3 \\
Splashed overo & 1 & 0 & 1 \\
Tobiano & 61 & 61 & 0 \\
Tovero & 11 & 8 & 3 \\
Solid-colored & 6 & 6 & 0 \\
\hline
\end{tabular}

and accurate, false positive results may arise. A false homozygous dominant result may have different implications in adult horses and foals. Since the condition is lethal when the mutation is found in homozygosity, a positive result would be impossible and easily interpreted as a false one in adults with no major implications. A false positive result in homozygous recessive all-white newborn foals, not yet presenting colic, is somewhat problematic because it might incur in gratuitous euthanasia if clinical decisions are based on genetic test result only, which is unlikely. The most problematic scenario would be a false positive result in all-white newborn foals exhibiting meconium retention or developmental gastrointestinal abnormalities, which are differential diagnoses for foals with OLWFS. In that case, it is critical that positive results are interpreted in conjunction with additional clinical data such as the resolution of clinical signs with appropriate therapy and the progression of the case. Meconium retention and congenital defects can be resolved after clinical or surgical treatment in the majority of cases [29-34], whereas colic episodes are recurrent and persistent in cases of OLWFS despite therapeutic attempts [5-7].

The HRM analysis clustered each unknown sample into one of the three possible genotypes with confidence $>90 \%$. The estimated frequency of heterozygotes was $21.6 \%$ (21/97), which is consistent with previous studies estimating the frequency of heterozygotes between $21.3 \%$ and $53.5 \%$ in APH and white-patterned horses in the United States, respectively $[16,17]$. All animals were classified with respect to gender and coat color pattern (Table 2). When the frequency of heterozygotes was analyzed by coat color pattern, we estimated low (27\%) and high $(89.5 \%)$ frequency of heterozygotes in toveros and overos, respectively. We did not observe any heterozygous horses with the tobiano or solid-colored coat color patterns. Horses with the tobiano, tovero, and overo coat color patterns have been associated with a low $(10 \%)$, intermediate $(58 \%)$, and high $(73 \%)$ frequency of heterozygotes for OLWFS in the United States, respectively [16]. Similarly to a previous study reporting a high frequency of heterozygotes $(>94 \%)$ in overo white spotting phenotypes [16], we estimated a frequency of heterozygotes greater than $83 \%$ in frame, calico, and sabino overos when considering only the overo sub-classifications. As expected for a sample containing only adult horses, we did not observe any positive calls for affected animals.

In conclusion, the HRM assay optimized in the present study resulted in a fast, accurate (sensitivity, specificity), and precise (repeatability, and reproducibility) diagnostic tool to detect the dinucleotide mutation in the EDNRB gene. The causative gene mutation of OLWFS is present in heterozygosity in the American paint horse population in Brazil and is highly frequent among overo horses.

\section{Declaration of conflicting interests}

None of the authors of this paper has a financial or personal relationship with other people or organizations that could inappropriately influence or bias the content of the paper.

\section{Funding}

The authors received no financial support for the research, authorship, and/or publication of this article.

\section{Acknowledgments}

We thank Dr. Priscila Fantini and Dr. Juliana de Souza Santos for helping us in the sample collection and with the laboratory procedures. We also would like to thank all veterinarians and/or owners who allowed us to sample horses on their stud farms.

\section{References}

[1] American Paint Horse Association, American Paint Horse Association's Guide to Coat Color Genetics, (2018) http://press.apha.com/pdfs/guidebooks/ ColorGenGuide.pdf , Accessed date: 6 October 2018.

[2] S.A. Brooks, T.L. Lear, D.L. Adelson, E. Bailey, A chromosome inversion near the KIT gene and the Tobiano spotting pattern in horses, Cytogenet. Genome Res. 119 (2007) 225-230.

[3] S.A. Brooks, R.B. Terry, E. Bailey, A PCR-RFLP for KIT associated with tobiano spotting pattern in horses, Anim. Genet. 33 (2002) 301-303.

[4] R. Hauswirth, B. Haase, M. Blatter, S.A. Brooks, D. Burger, C. Drogemuller, V. Gerber, D. Henke, J. Janda, R. Jude, K.G. Magdesian, J.M. Matthews, P.A. Poncet, V. Svansson, T. Tozaki, L. Wilkinson-White, M.C. Penedo, S. Rieder, T. Leeb, Mutations in MITF and PAX3 cause "splashed white" and other white spotting phenotypes in horses, PLoS Genet. 8 (2012) e1002653.

[5] D.L. Metallinos, A.T. Bowling, J. Rine, A missense mutation in the endothelin-B receptor gene is associated with Lethal White Foal Syndrome: an equine version of Hirschsprung disease, Mamm. Genome 9 (1998) 426-431.

[6] E.M. Santschi, A.K. Purdy, S.J. Valberg, P.D. Vrotsos, H. Kaese, J.R. Mickelson, Endothelin receptor B polymorphism associated with lethal white foal syndrome in horses, Mamm. Genome 9 (1998) 306-309.

[7] G.C. Yang, D. Croaker, A.L. Zhang, P. Manglick, T. Cartmill, D. Cass, A dinucleotide mutation in the endothelin-B receptor gene is associated with lethal white foal syndrome (LWFS); a horse variant of Hirschsprung disease, Hum. Mol. Genet. 7 (1998) 1047-1052.

[8] S.A. Brooks, E. Bailey, Exon skipping in the KIT gene causes a Sabino spotting pattern in horses, Mamm. Genome 16 (2005) 893-902.

[9] R. Hauswirth, R. Jude, B. Haase, R.R. Bellone, S. Archer, H. Holl, S.A. Brooks, T. Tozaki, M.C. Penedo, S. Rieder, T. Leeb, Novel variants in the KIT and PAX3 genes in horses with white-spotted coat colour phenotypes, Anim. Genet. 44 (2013) $763-765$.

[10] R.R. Bellone, G. Forsyth, T. Leeb, S. Archer, S. Sigurdsson, F. Imsland, E. Mauceli, M. Engensteiner, E. Bailey, L. Sandmeyer, B. Grahn, K. Lindblad-Toh, C.M. Wade, Fine-mapping and mutation analysis of TRPM1: a candidate gene for leopard complex (LP) spotting and congenital stationary night blindness in horses, Brief Funct Genom. 9 (2010) 193-207.

[11] A.T. Bowling, Dominant inheritance of overo spotting in paint horses, J. Hered. 85 (1994) 222-224.

[12] R.R. Bellone, Pleiotropic effects of pigmentation genes in horses, Anim. Genet. 41 (Suppl 2) (2010) 100-110.

[13] B.D. Hultgren, Ileocolonic aganglionosis in white progeny of overo spotted horses, J. Am. Vet. Med. Assoc. 180 (1982) 289-292.

[14] L. McCabe, L.D. Griffin, A. Kinzer, M. Chandler, J.B. Beckwith, E.R. McCabe, Overo lethal white foal syndrome: equine model of aganglionic megacolon (Hirschsprung disease), Am. J. Med. Genet. 36 (1990) 336-340.

[15] M.A. Ayala-Valdovinos, J. Galindo-Garcia, D. Sanchez-Chipres, T. Duifhuis-Rivera, New test for endothelin receptor type B (EDNRB) mutation genotyping in horses, Mol. Cell. Probes 30 (2016) 182-184.

[16] E.M. Santschi, P.D. Vrotsos, A.K. Purdy, J.R. Mickelson, Incidence of the endothelin receptor B mutation that causes lethal white foal syndrome in white-patterned horses, Am. J. Vet. Res. 62 (2001) 97-103.

[17] R.C. Tryon, M.C. Penedo, M.E. McCue, S.J. Valberg, J.R. Mickelson, T.R. Famula, M.L. Wagner, M. Jackson, M.J. Hamilton, S. Nooteboom, D.L. Bannasch, Evaluation of allele frequencies of inherited disease genes in subgroups of American Quarter Horses, J. Am. Vet. Med. Assoc. 234 (2009) 120-125.

[18] C.R. Newton, A. Graham, L.E. Heptinstall, S.J. Powell, C. Summers, N. Kalsheker, J.C. Smith, A.F. Markham, Analysis of any point mutation in DNA. The amplification refractory mutation system (ARMS), Nucleic Acids Res. 17 (1989) 2503-2516.

[19] J. Liu, S. Huang, M. Sun, S. Liu, Y. Liu, W. Wang, X. Zhang, H. Wang, W. Hua, An improved allele-specific PCR primer design method for SNP marker analysis and its application, Plant Meth. 8 (2012) 34

[20] G.H. Reed, J.O. Kent, C.T. Wittwer, High-resolution DNA melting analysis for 
simple and efficient molecular diagnostics, Pharmacogenomics 8 (2007) 597-608.

[21] P.A. Norambuena, J.A. Copeland, P. Krenkova, A. Stambergova, M. Macek Jr. Diagnostic method validation: high resolution melting (HRM) of small amplicons genotyping for the most common variants in the MTHFR gene, Clin. Biochem. 42 (2009) 1308-1316.

[22] P.R. Badial, J.P. Oliveira-Filho, N.J. Winand, A.S. Borges, Allele frequency of hereditary equine regional dermal asthenia in American Quarter horses in Brazil determined by quantitative real-time PCR with high resolution melting analysis, Vet. J. 199 (2014) 306-307.

[23] S. Garritano, F. Gemignani, C. Voegele, T. Nguyen-Dumont, F. Le Calvez-Kelm, D. De Silva, F. Lesueur, S. Landi, S.V. Tavtigian, Determining the effectiveness of High Resolution Melting analysis for SNP genotyping and mutation scanning at the TP53 locus, BMC Genet. 10 (2009) 5.

[24] Associação Brasileira do Cavalo Paint [Brazilian Paint Horse Association], Números de Paint Horse [Paint Horse Numbers], (2015) http://www.abcpaint.com.br , Accessed date: 1 September 2015.

[25] K. Nomoto, K. Tsuta, T. Takano, T. Fukui, T. Fukui, K. Yokozawa, H. Sakamoto, T. Yoshida, A.M. Maeshima, T. Shibata, K. Furuta, Y. Ohe, Y. Matsuno, Detection of EGFR mutations in archived cytologic specimens of non-small cell lung cancer using high-resolution melting analysis, Am. J. Clin. Pathol. 126 (2006) 608-615.

[26] M. Pichler, M. Balic, E. Stadelmeyer, C. Ausch, M. Wild, C. Guelly, T. Bauernhofer, H. Samonigg, G. Hoefler, N. Dandachi, Evaluation of high-resolution melting analysis as a diagnostic tool to detect the BRAF V600E mutation in colorectal tumors, J. Mol. Diagn. 11 (2009) 140-147.

[27] M. Krypuy, G.M. Newnham, D.M. Thomas, M. Conron, A. Dobrovic, High resolution melting analysis for the rapid and sensitive detection of mutations in clinical samples: KRAS codon 12 and 13 mutations in non-small cell lung cancer, BMC Canc. 6 (2006) 295.

[28] N. van der Stoep, C.D. van Paridon, T. Janssens, P. Krenkova, A. Stambergova, M. Macek, G. Matthijs, E. Bakker, Diagnostic guidelines for high-resolution melting curve (HRM) analysis: an interlaboratory validation of BRCA1 mutation scanning using the 96-well LightScanner, Hum. Mutat. 30 (2009) 899-909.

[29] C.S. Cable, S.L. Fubini, H.N. Erb, J.E. Hakes, Abdominal surgery in foals: a review of 119 cases (1977-1994), Equine Vet. J. 29 (1997) 257-261.

[30] N. Pusterla, K.G. Magdesian, K. Maleski, S.J. Spier, J.E. Madigan, Retrospective evaluation of the use of acetylcysteine enemas in the treatment of meconium retention in foals: 44 cases (1987-2002), Equine Vet. Educ. 16 (2004) 133-136.

[31] M.C. Mackinnon, L.L. Southwood, M.J. Burke, J.E. Palmer, Colic in equine neonates: 137 cases (2000-2010), J. Am. Vet. Med. Assoc. 243 (2013) 1586-1595.

[32] E.M. Santschi, Atresia coli in the foal, Equine Vet. Educ. 22 (2010) 438-438.

[33] K.L. Epstein, Congenital causes of gastrointestinal disease, Equine Vet. Educ. 26 (2014) 345-346.

[34] F. Toth, J. Schumacher, An overview of anal atresia and hypospadias in equids, Equine Vet. Educ. 27 (2015) 530-532. 